\title{
Lean for sustainable development in South Africa: A case study of three universities
}

\author{
Evelyn L. A. Allu \\ Department of Architecture, University of Jos, Jos- Nigeria. Email: evelynallu28@yahoo.com
}

Copyright (c) 2019 Allu. This article remains permanently open access under the terms of the Creative Commons Attribution License 4.0, which permits unrestricted use, distribution, and reproduction in any medium, provided the original work is properly cited.

Received 30th May, 2019; Accepted 22nd June, 2019

\begin{abstract}
Lean in higher education (LHE) is pursued for the reasons of improving efficiency and effectiveness of processes in High Education (HE). This review paper focuses on LHE within the university system to propose the implementation of lean culture and management into research and practices of South Africa universities, via a descriptive case study research method. The underpinning literature suggests that although the prospects of LHE has positive impact on both academic and non-academic practices in $\mathrm{HE}$, however, research has also acknowledged some challenges. These challenges include; lack of strategic planning and limited knowledge on the interpretation of the lean philosophy and implementation. Three universities were used as case studies to ascertain their areas of successes with LHE implementation. This paper contributes to the LHE discourse and offers an option for the South Africa universities to strategize for improved academic outcomes and effective administrative processes. South African has been acknowledged to lead its Sub-Saharan African region in research and thus, the integration of LHE in the universities' systems would positively impact this region and beyond. Furthermore, the paper recommends specific contextual adaptations of models tailored to meet individual institutional requirements and at the same time promote sustainable development.
\end{abstract}

Keywords: Lean, Lean Higher Education, prospects and challenges, sustainability, universities.

\section{INTRODUCTION}

The concept of sustainable development (SD) became world famous, as such some universities adopted its principles (Lozano, 2006). Subsequently, came the decade of Education for Sustainable Development (20052014) and the decade provided concepts for formal and non-formal education to promote SD at all settings (Laurie et al., 2016). Thus, many strategies continue to metamorphose leading to transformation in $\mathrm{HE}$ and particularly in the universities.

In the US where Lean Higher Education (LHE) historically started, there were some reasons driving its introduction into $\mathrm{HE}$, aside the attempts to improve efficiency and effectiveness of processes. The driving force was ascribed to:

For most American colleges and universities, the pendulum has swung from the heyday of growth, prosperity, and public favor to new times that call for institutions to adapt themselves to current, harsher realities.... The challenges of institutional change presented by the new environment are daunting. For institutions to be successful, change must be both intentional and continuous (Moore et al., 2007, p.120).

Lean Higher Education (LHE) is advancement for research and teaching, in that lean applications help to advance university-based processes towards improved services and efficiency through sustainable implementation. According to Hines and Lethbridge (2008), Balzer (2010) and Langer (2011), LHE became necessary because of the compelling demands of the changing structures and processes of Higher Education (HE). This is in addition to the need to transform the universities to meet up with increasing demand for; higher certification, performancebased competitions, sustainable globalization trends and the continuous shrinking of government funding for the 
university system (Browne 2010; Toma 2010; Balzer et al., 2015).

Invariably, LHE is geared towards value adding continuous improvement and efficiency of the HE sectors (Vukadinovic et al., 2017). Not addressing these daunting sustainable demands by any university would mean; backwardness in dealing with contemporaries issues, inability to source running cost of universities, inability to address problems and apply research outcomes that point at the potentials of implementing LHE.

In every business of which education is not an exception, there are three types of activities. According to Dragomir and Surugiu (2012, p. 279), these activities are:

1. Those that add value, are those activities which, from the customer, make a product or service more valuable;

2. The necessary activities that do not add value. Regarding the customer, such actions donot make a product or service more valuable, but from the point of view of the supplier, such activities cannot be eliminated; and

3. The additional actions that do not add value are those activities that can be removed.

The studies by Emiroğlu (2015) and Hodge (2015) went further to suggest that these business activities in government, healthcare and all other sectors use the lean thinking as an effective management strategy for eliminating processes that do not add value. In the education business, LHE was evolved to cater for these needs as discussed in the subsequent sections.

These expectations and demands make the implementation of leanness the most appropriate strategy for improvements and efficiency in the universities system. This is because the university promotes development in all facets of life and hence, it must be seen to encourage SD in its activities (Allu and Emuze, 2017).

In addition to the aforementioned, education has been identified as key and catalyst for SD (UNESCO, 2014) and LHE as strategy for improving performance and processes in higher education institutions. Balzer et al. (2016, p. 443) further observed that LHE implementation and management can advance the university community in areas that include;

...student admissions, hiring faculty, purchasing supplies, offering a new major, remodelling a research lab, adding or dropping a course, approving a grant submission, advising students or communicating with donors.

The lean philosophy or lean thinking and implementation have been integrated into many development sectors for over two decades. However, the application of lean as LHE in HE is still at its infancy (Antony et al., 2012) and Runyan (2017) notes that the integration of LHE into the university system only began in 2013 . This is possibly why not much is known about LHE in the research circles in Africa.

Earlier studies have acknowledged that there are evidences on the success and improvements within university communities who engage with LHE in response to the many demands and changes required of a university system (Isaksson et al., 2013; Emiliani, 2016; Yorkstone, 2016; Vukadinovic et al., 2017). However, a recent research observed that before its study was published, there was no systematic review research on the integration of LHE and for the proposed implementation of LHE in the university system (Balzer et al., 2016). As such, this paper adds to the discourse on the subject and support the call for the integration of LHE in the South African universities as is tenable elsewhere globally to promote sustainably improvement of services and efficiency of university activities within the South African universities and other African countries.

The rationale for South African context was for the reason that it leads in research and innovations amongst its other African countries. Some researchers have acknowledged this (Nicolaides, 2014; Awuzie and Emuze, 2017). Thus, when South African universities adopt and integrate LHE, it is expected that it would be easier for other African countries to adapt same because of the similarities in their contextual settings.

This study seeks to present its discourse from three angles. Firstly, it engages in theoretical discussion around its main key words. Secondly, it discusses some areas of successes and challenges with LHE implementation; this was carried out to recommend ways to overcome the barriers. Thirdly, three selected universities are presented as case studies, focusing on their areas of success to illustrate and underpin the argument for this paper's discourse.

The paper concludes with the proposal that, integrating and implementing LHE into the university system of the South African universities is not an option but a necessity. This proposal is suggested as a result of the successes deduced from the selected top universities which served as case studies.

\section{Adapting LHE principles to university processes}

The university is part of $\mathrm{HE}$ and it incubates what the future holds. This is because the university goes beyond training and research to; shaping of minds, creating the future leaders and intellectuals for all sectors of developments (Loranzo, 2007). The introduction of LHE into the universities was aimed at enhancing; students and students support services, revenue drive, teaching and research processes, and system-wide improvements and efficiency (Balzer et al., 2017a). Also, LHE promotes sustainable actions (Yorkstone, 2016) and the integration of lean to any process supports SD (Allu and Emuze, 2018).

Awuzie and Emuze (2017) have observed the increase 
in sustainable oriented strategy amongst the South African $\mathrm{HE}$ and also noted their willingness to align and support the national government SD aspirations. Hence, the assumption of this paper that the South African universities are well positioned to adapt and implement LHE.

Balzer (2010) has identified reasons for which LHE is needed as follows:

1. Many university processes are failing to meet the needs of those they serve (e.g., parents, students, faculty, department chairs, campus offices, donors, employers, and alumni).

2. Many university processes are perceived to be extremely slow, and individuals and offices involved in these processes are often seen as adding more time but little additional value.

3. Many university processes involve multiple vice with each work on their part of the process, with no single "owner" responsible for ensuring that the process works efficiently and effectively.

4. Typical responses to complaints of failures of university processes require an individual with authority (but little contact with the process) to intervene and handle the complaint outside of the official process. Staff time spent helping administrators resolve these complaints delays help for those who are in the standard process queue and waiting patiently.

5. Documentation is poor for many university processes, with no standardized written instructions or employee training programs that establish clear expectations for each of the steps and activities contributed by employees to each process.

6. Many university processes fail to benefit from the insights and recommendations of the employees who are intimately involved in the process but have no formal mechanism to share their concerns and suggestions.

7. Many universities have not established a climate that helps transform the institution into a learning organization that regularly improves itself to serve the individuals and organizations that are the beneficiaries of their work (Balzer, 2010, p. 7).

The enumerated problems resonate with the South Africa context. These contextual problems include; limited knowledge and scarce resource for funding $\mathrm{HE}$, students logging the university systems which further reduce the university capacity to earn subsidy, limited transformation agendas, overall minimal staff motivation and inadequate mechanisms to ensure sustainable actions/tasks leading to SD (Malanda, 2015; Kruger, 2016; Allu and Emuze, 2018).

Given these concerns in the present day internationalization demands, the sustainable aspirations of the South African national government and scarce resource common to Sub-Saharan African countries, there is need for an improvement in the services of universities' structures and processes. However, proactive actions are needed particularly planning, because it prepares the people and directs the university on how and where to start the integration process of LHE.

The introduction of LHE as aforementioned was to improve academic outcomes, administrative efficiency, reduce time wastage, promote cost effectiveness and sustainable practices. A research from a South African university in its conclusion stated thus:

"...South African higher education institutions are not ready yet to start implementing the Lean Thinking within their management. Despite the fact that they can commit to some of the requirements for a successful Lean Thinking implementation, they do not perceive well the practices of its philosophy" (Malanda, 2015, p.120).

The quotation above supports the observations of Awuzie and Emuze (2017) on the one hand- the commitment to sustainability. On the other hand, suggest sluggishness amongst the South African universities to align with its government on the implementation of lean strategies, which in themselves promote SD. This may be linked to Liker and Belle (2013) assertion that, it is not enough to apply lean tools to processes but to reorient employees to develop kaizen (continuous improvement) spirit approach to problem-solving.

\section{Lean Higher Education (LHE) and sustainability}

In recent years, the education service sector has evolved sustainability in its services (Gibbs, 2013). Currently, according to Green (2013), the sustainability drive for universities revolves around; businesses of academic service demands and the importance of innovations in educational services, which has become an important business that requires lean strategies. Lean implementation started in the early 2000s in the United States of America (USA) and because of the improvements recorded, many universities have recently begun pursuing the lean culture. The reasons for the pursuant were; for increasingly effective and efficient services and processes (Yorkstone, 2016). As such, research started to look into understanding how lean can be applied to Higher Education (HE) and particularly to the university context (Langer, 2011).

\section{Linking Lean to sustainable development}

The principles of lean promote sustainable development. The pursuits of Sustainable Development (SD) through lean integration and implementation has been acknowledged in earlier studies (Ahuja et al., 2017; Allu and Emuze, 2018). Also, researchers have suggested that 
integrating lean principles and context to development, ensures new standards for excellence for continuous sustainable developments (Patty and Denton, 2010; Dinesh et al., 2017). Furthermore, the application of lean to any form of developments improves the traditional development processes and practices including training (Abdelhamid, 2007; Jamil and Fathi, 2016). Therefore, since lean promotes SD, it is evident then, that they are linked, because they both are aimed at ensuring improvements in the processes, practices and the future outcomes of developments, be it in businesses or education.

\section{Prospects of Lean implementation in university system}

Implementing lean through LHE has many benefits. The benefits include the following:

1. Staff training: creates a sense of belonging to all employers in the university and thus, harmonizes targets (More et al., 2007; Carter et al., 2011).

2. Saves and increases revenue: resulting from improved customer services and increased revenue generation (More et al., 2007; Diamond, 2015).

3. Student satisfaction: students are beneficiaries of the impacts of improvements and efficiency in university services (teaching, learning and administrative services); which relates to the students directly (Emiliani, 2016).

4. Personnel performance improvements: the overall morale and work ethic of employees in areas where changes have been made are improved significantly (Thomas, 2009; Bortollotti et al., 2015).

5. Faculty satisfaction: academic staff are benefiting from the improved processes and enrolments management (More et al., 2007).

6. Saves time: waiting time is reduced (Isaksson et al., 2013; Diamond, 2015).

7. Promotes sustainability: identified benefits are pursued for continuous improvement (Yorkstone, 2016).

8. Lean culture and mind-set: the university has become an important part of the building and reorientation of the mind-set of its immediate community and the future of the society towards a lean culture (Yorkstone, 2016).

9. Curriculum improvement: mainstreaming lean into curriculum makes lean a part of the everyday activity (Balzer, 2010).

10. Transaction and administrative processes: LHE easily improves the administrative offices particularly for accounting and financial transactions (Svensson et al., 2015).

11. Assessment processes: when LHE is aligned with courses, it has the capacity to improve student assessment via processes of learning outcome/ objectives and performance criteria or specifications (El-Sayed et al., 2015).

12. Productive efficiency and economic soundness: lean integration in HE promotes efforts towards outcome that are efficient and have economic soundness (Bortollotti et al., 2015) and thus, reduces wastages.

13. Planning: errors associated with the control and planning of activities such as conferences and other training initiatives are improved when LHE principles are institutionalized into university system (Balzer et al., 2016).

14. Distance learning: LHE offers improvements in educational distance learning processes that mostly deal with mature students who may not have much time for rigors of full-time studies (Isaksson et al., 2013).

15. Quality and reduced cost: LHE applies the lean philosophy, which promotes quality and reduces cost of running HE (Vukadinovic et al., 2017).

\section{Barriers challenging LHE}

The integration of LHE into the university system was introduced in 2013 and the western universities are in the forefront in its integration (Runyan, 2017). Starting the process of integrating lean at a university has been noted to be a 'daunting task' because of the change required from a non- hierarchical structure to adapting the Toyota Production System model, which has hierarchical structure (Salewski and Klein, 2009) and thus, implementing LHE also has its challenges.

The challenges for integrating LHE in universities include; misinterpretation and misconception of the lean concept by players (Dragomir and Surugiu, 2012; Torbjorn et al., 2017), thus weakening the improvement purpose of lean. Other challenges reported include; resistance to change associated with established culture and lack of management support (Emiliani, 2015; Wiegel and Brouwer-Hadzialic, 2015). In addition, LHE is perceived to have a long-term strategy in its planning and outcomes (Isaksson et al., 2013) and the perception of lean as a fixed set of tools (Hines et al., 2004; Langer, 2011). Also, Thirkell and Ashman (2014) found out that, the main challenges are; communication, understanding and on how to apply leanness. Whilst, Balle (2017) emphasizes the important role of the people within a system, as a fundamental requirement for any improvement strategy to be adopted.

These barriers are all human related and linked to; misunderstanding and implementation of the lean philosophy. As such, much are needed to be done in the areas of capacity building through knowledge, awareness and bringing to the public domain the successes of integrating lean ethos in every human development 
activities and particularly in the university systems which are seen as drivers of knowledge, developments and positive change.

\section{RESEARCH DESIGN AND METHODS}

Since the focus of the paper is LHE within the university systems, a descriptive case study research method is adopted. Descriptive case studies according to Stjelja (2013, p.4): "are very focused and detailed, as they carefully assess a case based on a descriptive theory." In this paper the underpinning literature established that there are successes in the integration of LHE and hence, some universities which are leading in the implementation of LHE are selected. In this section, how the successes were achieved and described based on the evidences from literature from these universities.

This paper presents three case studies from three universities, which have integrated or institutionalized the implementation of LHE in their activities. The case studies uncover how these institutions were able to implement LHE in their services to students, staff and the public. Academic papers with a qualitative study design were also reviewed in order to understand the in-depth inquiry and robust descriptions of the subject discourse therein (Bygballe and Swärd, 2014).

Table 1, presents the three case studies; Bowling Green State University-USA, University of St Andrews, UK and University of Queensland, Australia. These universities were chosen because they have been recognised as some of the leading universities in the implementation of the LHE agendas (Bygballe and Swärd, 2014). Secondly, each of the three universities like the South African universities had resonated with some problems, for which the LHE implementation has improved upon by adding value to its services in terms of service continuous improvement and efficiency. Three areas of, strategy/methods, problems/goals and the outcomes were used to valid the theoretical underpins and to provide the discourse leading to recommendations. Thus, Table 1 outlined the specific methods employed by each university for the implementation of LHE and their achievements are presented as outcomes.

\section{DISCUSSION OF FINDINGS}

It is notable, that for each of the three universities, there were a number of problems that required improvements either in their services and or in the efficiency required. These problems identified ranges from attempts to; reduce waste in all university processes, streamline processes for effectiveness procedures, improve efficiency and effectiveness in all present and future activities and its staff. The identification spurred conscious efforts and planning from the universities studied to strategize for the implementation of LHE using a small team for a start. This proactive action reduced the seemly daunting task of implementing lean thinking or culture among university staff as shown on the outcomes column in Table 1.

Following Salewski and Klein (2009) argument on the challenges for implementation of LHE, the successes from the case studies proved that these challenges can be subjugated and therefore not excusable. The perceived long-term of nature planning required for LHE integration must be seen as a potential rather than a challenge because of the long-run benefits. The LHE integration needs to be pursued as a motivation for continuous improvement and efficiency in the university system. From Table 1, it has been established that the three universities had outlined their goals and strategized on how to achieve it. Clearly, this shows that lean led strategies for improvements through LHE integration and implementation requires planning as was suggested in the discourse.

The outcomes from these universities validate the underpinning literature presented in the preceding sections. The prospects and advantages of implementation LHE were clearly shown in Table 1 to include; reduction in the time spent for university tasks and wastages in university system processes (Isaksson et al., 2013; Diamond, 2015; Bortollotti et al., 2015). Training and learning has been reported to have improved with the implementation of LHE, so much that, successes were recorded amongst the universities' business processes, research and administration.

In general, the benefits of implementing LHE in universities are profitable. This is because the universities as a system where LHE is adopted enjoys continuous; improvement and efficiency of its services, building capacities and morale for students and staff, enhancing collaborations and SD practices (Robinson and Yorkstone, 2014; Balzer et al., 2017b; Visser and Shannon, 2017).

As per the literature covered, a larger number focused on the implementation of LHE for the HE in general, only studies that focused on universities were used for the descriptive analysis of the case studies. In the case of University of St Andrews- UK, the university is able to develop a model to suit its purpose (Colvin et al., 2010) invariable that means, other universities are able to do the same. Therefore, the South African universities have no reason for lukewarm disposition towards adopting LHE and hence, its pursuit by this study.

\section{Conclusion and recommendations}

Although lean has been a manufacturing adaptation, globally businesses and later universities have successfully adapted its concepts/principles to advance value adding pursuits. In the education sector, LHE was evolved and even though recent, its successes proved that the strategy is capable of advancing SD through the many 
Table 1. Three Case Studies of LHE universities.

\begin{tabular}{|c|c|c|c|c|c|c|}
\hline $\mathrm{S} / \mathrm{N}$ & University & Source & Year & $\begin{array}{l}\text { Strategy/ } \\
\text { method }\end{array}$ & Problems/Goals & Outcomes (highlights) \\
\hline 1 & $\begin{array}{l}\text { Bowling } \\
\text { Green State } \\
\text { University } \\
\text { USA. }\end{array}$ & $\begin{array}{l}\text { Balzer et al., } \\
(2017 b) \text {. }\end{array}$ & 2006 & $\begin{array}{l}3 \text { members of } \\
\text { faculty and } 1 \\
\text { Doctoral student }\end{array}$ & $\begin{array}{l}\text { i. To reduce waste in all } \\
\text { university processes. } \\
\text { ii. To improve efficiency and } \\
\text { effectiveness in all activities. }\end{array}$ & $\begin{array}{l}\text { - Reduction in time wastage } \\
\text { and transfers. } \\
\text {-Significant reductions for } \\
\text { student retention and staff } \\
\text { positions. }\end{array}$ \\
\hline \multirow{3}{*}{2} & \multirow{3}{*}{$\begin{array}{l}\text { University of } \\
\text { St Andrews, } \\
\text { UK. }\end{array}$} & \multirow{3}{*}{$\begin{array}{l}\text { Robinson \& } \\
\text { Yorkstone, } \\
\text { (2014). }\end{array}$} & \multirow{3}{*}{2006} & \multirow{3}{*}{$\begin{array}{l}3 \text { Lean Team } \\
\text { members }\end{array}$} & \multirow{3}{*}{$\begin{array}{l}\text { i. Culture Change: to create } \\
\text { a drive and appetite for } \\
\text { continuous improvement. } \\
\text { ii. Effectiveness: to ensure } \\
\text { that all institutional } \\
\text { processes meet existing and } \\
\text { emerging needs. } \\
\text { iii. Efficiency: to maximise } \\
\text { the use of all resources in } \\
\text { the delivery of high quality } \\
\text { services. }\end{array}$} & $\begin{array}{l}\text {-Optimised improvement in } \\
\text { all areas (Training, business } \\
\text { processes, learning, } \\
\text { research and } \\
\text { administration). }\end{array}$ \\
\hline & & & & & & $\begin{array}{l}\text { - The St Andrews Model was } \\
\text { developed known as } \\
\text { "Becoming }\end{array}$ \\
\hline & & & & & & $\begin{array}{l}\text { Lean: Pocket Guide". } \\
\text { (Colvin et al., 2010). }\end{array}$ \\
\hline \multirow{5}{*}{3} & \multirow{5}{*}{$\begin{array}{l}\text { University of } \\
\text { Queensland, } \\
\text { Australia. }\end{array}$} & \multirow{5}{*}{$\begin{array}{l}\text { Visser \& } \\
\text { Shannon } \\
(2017)\end{array}$} & \multirow{5}{*}{2015} & \multirow{5}{*}{$\begin{array}{l}\text { Number of } \\
\text { Team members } \\
\text { not stated }\end{array}$} & \multirow{5}{*}{$\begin{array}{l}\text { i. The need to streamline its } \\
\text { processes for scheduling } \\
\text { elective procedures in the } \\
\text { university's Veterinary } \\
\text { Medical Centre. } \\
\text { ii. To promote continuous } \\
\text { improvements for processes } \\
\text { and people. }\end{array}$} & $\begin{array}{l}\text { •Significant communication } \\
\text { improvement and feedback. }\end{array}$ \\
\hline & & & & & & $\begin{array}{l}\text {-Observable increase in } \\
\text { respectful interactions } \\
\text { between staff }\end{array}$ \\
\hline & & & & & & $\begin{array}{l}\text {-Observable increase in staff } \\
\text { working collaboratively to } \\
\text { solve problems. }\end{array}$ \\
\hline & & & & & & $\begin{array}{l}\text {-Observable increase in staff } \\
\text { using data as objective } \\
\text { starting point in solving }\end{array}$ \\
\hline & & & & & & Problem. \\
\hline
\end{tabular}

Source: Author's arrangement.

improvement opportunities it offers to the university systems. As such, every educational activity needs to be linked to SD. Non-compliance by any university would mean regression rather than progression within the university system and as such surcharge its students and the future. Furthermore, each university is required to contextualize their adoption for effective transformation of their individual system sustainably. This therefore is not an option for the South African Universities who have always led other African universities in sustainable pursuits.

This discourse has established the benefits of LHE implementation into the university systems, the paper reported on how some universities were able to implement LHE and their successes validated the underpinning theoretical findings. Although, lean and LHE has been around for more than a score and a decade respectively, the LHE integration into the university system has been quite recent and requiring long term planning. However, in the overall its pursuit is relevant, necessary and requires no hesitation as was observed. This is even more important to South Africa being in the led on lean research within the Sub-Saharan African region. Therefore, its universities must demonstrate and continue to lead in the philosophical implementation of LHE in order to display the practicality therein and to improve; its academic outcomes, support services to its students, researchers and the public/clients.

Recommendations are drawn from the discourse and are offered for the proposed adaptations to universities and particularly the South African university system which is the context of this discourse. Firstly, for universities to embrace the opportunities presented and benefit from the value adding strategies of implementing LHE in the university system. Secondly, universities are encouraged to pursue LHE integration/implementation as a performance strategic for university systems continuous improvement and efficiency. Thirdly, it is necessary to develop blue print for each university system which 
involves every stakeholder within the system. Fourthly, after adapting LHE each university should ensure periodic progress report and evaluation mechanisms are institutionalized to keep checks of areas needing finetuning for continuous improvement. Finally, by so doing, the sustainment at all levels of all operations and processes are not only ensured but are also sustainably pursued. Hence enhancing and sustaining the sustainable development strife noted in the South African universities.

Future studies should include other methodologies. Qualitative inquiries and studies that would assist in measuring the tangible impact of LHE integration into university systems are suggested to further advance research in this regard.

\section{CONFLICT OF INTEREST}

The author declares that there is no conflict of interest.

\section{REFERENCES}

Abdelhamid, T. (2007). Lean Construction Principles. Graduate Class Offering at Michigan University. Available at www.slideshare.net/tabdelhamid/lean-constructionintroduction. Accessed 12/4/2017.

Ahuja, R., Sawhney, A., \& Arif, M. (2017). Prioritizing BIM capabilities of an organization: An interpretive structural modeling analysis. Procedia Engineering, 196, 2-10.

Allu, E. L. A. and Emuze, F. A. (2017). Towards sustainable architectural education in Nigeria: Challenges and potentials A Review. Journal of Contemporary Research in the Built Environment, 1(2), 115-123.

Allu, E. L. A., \& Emuze, F. A. (2018). Advancing Lean Implementation for Improving sustainability the AEC Sector: A Literature Review. Sustainability: The Journal of Records, 11(3), 127-135.

Antony, J., Krishan, N., Cullen, D., \& Kumar, M. (2012). Reflective practice - lean six sigma for Higher Education Institutions (HEls) challenges, barriers, success factors, tools/techniques. International Journal of Productivity and Performance Management, 61(8), 940-948.

Awuzie, B., \& Emuze, F. (2017). Promoting sustainable development implementation in higher education universities in South Africa. International Journal of Sustainability in Higher Education, 18(7), 1176-1190.

Balle, M. (2017). How can i tell good lean consultants from bad? Lean Enterprise Institute.

Balzer, W. K. (2010). Lean Higher Education: Increasing the value and performance of university processes, CRC Press, Boca Raton, FL.

Balzer, W. K., Brodke, M. H., \& Kizhakethalackal, E. T. (2015). Lean Higher Education: Successes, challenges, and realizing potential. International Journal of Quality and Reliability Management, 32(9), 924-933.

Balzer, W. K., Francis, D. E., Krehbiel, T. C., \& Shea, N. (2016). A Review and perspective on lean in higher education. Quality Assurance in Education, 24(4), 442-462.

Balzer, W. K., Krehbiel, T. C., \& Krehbiel, T. C. (2017a). Lean applications in higher education-Part Two. Available at https://the-Imj.com/2017/03/lean-applications-in-higher- education-part-two/. Accessed 21/2/2018.

Balzer, W. K., Krehbiel, T. C., \& Krehbiel, T. C. (2017b). Lean applications in higher education-Part One. Available at https://the-Imj.com/2017/03/lean-applications-in-highereducation-part-one/

Bortollotti, T., Boscari, S., \& Danese, P. (2015). Successful lean implementation, organisational culture and soft lean practice. International Journal of Production Economics, 160, 182-201.

Bygballe, L. E., \& Swärd, A. (2014). Implementing lean construction: A practice perspective. Proceedings IGLC-22, June 2014, 3-14

Carter, B., Danford, A., Howcroft, D., Richardson, H., Smith, A., \& Taylor, P. (2011). Lean and mean in the civil service: The case of processing in HMRC. Public Money and Management, 31(2), 115-122.

Colvin, L., Robinson, M., \& Yorkstone, S. (2010). Becoming Lean: Pocket Guide. Available at http://www.standrews.ac.uk/media/lean/documents/Becoming LeanAugust2012.pdf. Accessed 20/2/2018.

Diamond, I. (2015). Working smarter 2015. UK: Universities Scotland.

Dinesh, S., Sethuraman, R., \& Sivaprakasam, S. (2017). The review on lean construction an effective approach in construction industry. Special Issue, Pp. 119-123

Dragomir, C., \& Surugiu, F. (2012). Implementing lean in a higher education university. Analele Universitatii Maritime Constanta, 13(18), 279-282.

El-Sayed, M., El-Sayed, J., Morgan, J., \& Cameron, T. (2011). Lean program and course assessments for quality improvement. International Journal of Process Education, 3(1), 65-72.

Emiliani, M. L. (2015). Lean University: A guide to renewal and prosperity. The CLBM, LLC, Wethersfield, CT.

Emiliani, M. L. (2016). Evolution in lean teaching. Available at https://bobemiliani.com/wpcontent/uploads/2016/09/elt_paper.pdf. Accessed 15/3/2018.

Emiroğlu, A. (2015). Strategy, operations strategy and lean manufacturing. International Journal of Social Science, 37, 409-419.

Green, D. A. (2013). Academic development in the evolution of higher education. International Journal for Academic Development, 18(3), 205-207.

Hines, P., \& Lethbridge, S. (2008). New development: Creating a lean university. Public Money and Management, 28(1), 53-56.

Hines, P., Holweg, M., \& Rich, N. (2004). Learning to evolve: A review of contemporary lean thinking. International Journal of Operations and Production Management, 24(10), 994-1011.

Hodge, S. (2015). Fact Vs. fiction: Why lean isn't part of every management strategy. Available at http://www.sixsigmadaily.com/why-lean-isnt-part-of-everymanagement-strategy/. Accessed 15/3/2018.

Isaksson, R., Kuttainen, C., \& Garvare, R. (2013). Lean higher education and lean research. Angelo Conference Proceedings, 16th Toulon-Verona Conference "Excellence in Services" University of Ljubljana, Slovena, 29-30 August 2013, Pp. 380-391.

Jamil, A. H. A., \& Fathi, M. S. (2016). The integration of lean construction and sustainable construction: A Stakeholder perspective in analyzing sustainable lean construction strategies in Malaysia. Procedia Computer Science, 100, 634643.

Kruger, D. (2016). Lean utilisation for streamlining processes in the higher education sector in South Africa. 2016 Proceedings of PICMET 2016: Technology Management for Social 
Innovation. Available at http://ieeexplore.ieee.org/stamp/ stamp.jsp?tp=\&arnumber $=7806618$. Accessed 20/2/2018.

Langer, T. (2011). The application of lean thinking for improving processes in higher education institutions: Evidence from three UK case studies. Thesis, MSc Management, Queen's University Belfast, UK.

Laurie, R., Nonoyama-Tarumi, Y., McKeown, R., \& Hopkins, C. (2016). Contributions of education for sustainable development (ESD) to quality education: A synthesis of research. Journal of Education for Sustainable Development, 10(2), 226-242

Liker, J., \& Balle, M. (2013). Lean managers must be teachers. Journal of Enterprise Transformation, 3(1), 16-32.

Loranzo, R. (2007). Incorporation and institutionalization of SD into universities: Breaking through barriers to change. Journal of Cleaner Production, 14, 787-796.

Malanda, J. N. (2015). The applicability of lean thinking in a few South African universities. MSc. Unpublished, University of Johannesburg. Available at http://hdl.handle.net/10210/14526. Accessed 19/2/2018.

Moore, M., Nash, M., \& Henderson, K. (2007). Becoming a lean university. Best practices of Southern Association of College and University Business Officers (SACUBO). Available at www.okyanusbilgiambari.com/.../LeanUniversity.Becoming. U nivofCentralOkla.pdf. Accessed 2/2/2018.

Nicolaides, A. (2014). Research and innovation - The drivers of economic development. African Journal of Hospitality, Tourism and Leisure, 3(2), 1-16.

Patty, R. M., \& Denton, M. A. (2010). End of project overruns. Universal, Boca Raton, Florida.

Robinson, M., \& Yorkstone, S. (2014). Becoming a lean university: The case of the University of St Andrews. Leadership and Governance in Higher Education, 1, $42-71$.

Runyan, V. (2017). Lean in higher education: Improving Macquarie University. Available at http://planet-lean.com/leanin-higher-education-improving-macquarie-university. Accessed 21/2/2018.

Salewski, A., \& Klein, V. (2009). How to Launch Lean in a University. Available at http://asq.org/edu/2009/06/baldrigenational-qualityprogram/how-to-launch-lean-in-a-university. pdf. Accessed 15/3/2018.

Stjelja, M. (2013). The case study approach: Some theoretical, methodological and applied considerations (No. DSTO-TN1188). Defence Science and Technology Organisation Edinburgh (Australia) Land Operations Division. Available at www.dtic.mil/get-tr-doc/pdf?AD=ADA588465. Accessed 21/2/2018
Svensson, C., Antony, J., Ba-Essa, M., Bakhsh, M., \& Albliwi, S. (2015). A lean six sigma program in higher education. International Journal of Quality and Reliability Management, 32(9), 951-969.

Thomas, I. (2009). Critical thinking, transformative learning, sustainable education, and problem-based learning in universities. Journal of Transformative Education, 7(3), 245264.

Thirkell, E., \& Ashman, I. (2014). Lean towards learning: connecting lean thinking and human resourse management in UK higher education. International Journal of Human Resource Management, 25(21), 2957-2977.

Toma, J. D. (2010). Building organizational capacity: strategic management in higher education. The Johns Hopkins University Press, Baltimore.

United Nations Educational, Scientific and Cultural Organization (UNESCO) (2014). Sustainable development begins with education. Available at www.unesdoc.unesco.org/images/0023/002305/230508e.pdf. Accessed 07/02/2018.

Visser, M., \& Shannon, C. (2017). Implementing LEAN at the veterinary teaching hospital. Lean HE Conference 2017. Available at http://www.cvent.com/events/lean-in-highereducation-conference-implementing-measuring-andsustaining-change/speakers-

2b123c33155944f1a389512ad55eb85a.aspx. Accessed 2/3/2018.

Vukadinovic, S. Djapan, M., \& Macuzic, I. (2017). Education for lean and lean for education: A literature review. International Journal for Quality Research, 11(1), 35-50.

Wiegel, V., \& Brouwer-Hadzialic, L. (2015). Lessons from higher education: Adapting lean six sigma to account for structural differences in application domains. International Journal of Six Sigma and Competitive Advantage, 9(1), 72-85.

Yorkstone, S. (2016). Lean universities. The Routledge companion to Lean management. Abingdon: Taylor \& Francis (Routledge), NY. ISBN: 978-1138920590. 